\title{
Adolescent health: Priorities and opportunities for Rashtriya Kishor Swasthya Karyakram
}

Sapna Desai

Population Council

Follow this and additional works at: https://knowledgecommons.popcouncil.org/departments_sbsr-pgy

Part of the Demography, Population, and Ecology Commons, Domestic and Intimate Partner Violence Commons, Family, Life Course, and Society Commons, and the International Public Health Commons How does access to this work benefit you? Let us know!

\section{Recommended Citation}

Desai, Sapna. 2017. "Adolescent health: Priorities and opportunities for Rashtriya Kishor Swasthya Karyakram," Policy brief, Bihar. New Delhi: Population Council. 


\section{Adolescent health \\ Priorities and opportunities for Rashtriya Kishor Swasthya Karyakram}

\section{Introduction}

The Government of India in 2014 signaled its commitment to adolescent health through introduction of a national strategy, Rashtriya Kishor Swasthya Karyakram (RKSK). Targeting adolescents in ages 10-14 and 15-19, the programme aims to ensure universal coverage of health information and services for all adolescents-those in and out of school, married or unmarried, and vulnerable groups. Envisaged as a paradigm shift to address adolescent health beyond sexual and reproductive health, RKSK spans six domains: nutrition, sexual and reproductive health, mental health, injuries and violence including gender-based violence, substance misuse, and non-communicable diseases (NCDs). This policy brief presents evidence on adolescent health from 2016 on the six RKSK priority areas, providing a baseline profile for the programme in Bihar.

\section{Key Findings}

RKSK's strategy is aligned with the health burden found by the UDAYA study. Key issues are:

- Low levels of knowledge regarding sexual and reproductive health across all adolescents

- $\quad$ Distinct sexual and reproductive health risks that vary by marital status, age, and sex

- High prevalence of anaemia, especially amongst older and younger girls

- Mental health issues and intimate partner violence amongst married girls

- $\quad$ Tobacco use and injuries amongst older boys

Services are weak. Challenges include:

- $\quad$ Low engagement with frontline workers and very limited utilisation of Adolescent Friendly Health Clinics

- Ensuring peer educators can facilitate information exchange and increased use of services

- Developing a sustainable recruitment and training plan for peer educators

Key opportunities for RKSK:

- Improve awareness, strengthen or revamp service delivery, and evaluate outreach strategies

\section{The UDAYA study}

Understanding the lives of adolescents and young adults (UDAYA), a programme of research conducted by the Population Council, seeks to explore the situation and needs of younger (10-14 years) and older (15-19 years) adolescents, describe changes in their situation and needs over time, and assess factors that determine how they transition from adolescence to young adulthood. In Bihar, the study includes a longitudinal and cross-sectional component, a policy and programme landscaping and qualitative substudies. In 2016, the Population Council collected quantitative data from (a) a sample of adolescents who were first interviewed in 2007 when they were 15-19 years, and were 2327 years old at the time of this survey and (b) a fresh sample of unmarried girls and boys (10-14 and 15-19 years) and married girls in ages 1519 years. In 2018-19, we will reinterview this group, when they will be in ages $13-17$ and $18-22$, as well as collect data from a fresh sample of unmarried boys and girls (10-14 and 15-19 years) and married girls (15-19 years). This brief presents findings from the landscaping exercise and descriptive analyses of the 2016 cross-sectional sample of 10,433 adolescents. Anthropometric measurements and haemoglobin testing were also conducted among a sub-sample of participants. 


\section{RKSK Strategy}

The RKSK strategy expands a previous focus on curative care for adolescents to health promotion and prevention activities, primarily through established platforms such as frontline workers (FLWs) and youth clubs. New initiatives at the community level supported by RKSK include an Adolescent Health Day and a helpline. The strategy also calls for states to recruit dedicated counsellors at adolescent friendly health clinics (AFHCs) and at least four peer educators per village to establish groups, conduct participatory sessions and facilitate referrals to AFHCs. Lastly, RKSK promotes coordination of activities for adolescents, both within Health and Family Welfare and across programmes, such as with Women Development Corporation and Youth Affairs and Sports.

\section{Persistent Burdens: Anaemia and poor sexual and reproductive health}

\section{Nutrition}

Malnutrition and anaemia were common amongst adolescents (Table 1). Close to 3 in 10 boys between 10-14 years were classified as thin. While thinness was less prevalent amongst girls, moderate or severe anaemia was detected in 1523 percent of girls in ages 15-19. Less than three percent of adolescents were overweight or obese, with a slightly higher prevalence in urban areas.

Table 1: Nutritional status amongst adolescents

\begin{tabular}{|lccccc|}
\hline $\begin{array}{l}\text { Nutritional } \\
\text { Indicator }\end{array}$ & $\begin{array}{c}\text { Boys } \\
(10-14)\end{array}$ & $\begin{array}{c}\text { Boys } \\
(15-19)\end{array}$ & $\begin{array}{c}\text { Girls } \\
(10-14)\end{array}$ & $\begin{array}{c}\text { Unmarried } \\
\text { girls } \\
(15-19)\end{array}$ & $\begin{array}{c}\text { Married } \\
\text { girls } \\
(15-19)\end{array}$ \\
\hline Thinness & 28.3 & 23.3 & 17.3 & 9.3 & 6.7 \\
\hline Mild anemia & 23.4 & 15.9 & 47.8 & 53.5 & 42.3 \\
$\begin{array}{l}\text { Moderate/ } \\
\text { severe anemia }\end{array}$ & 2.9 & 8.7 & 10.0 & 15.0 & 22.6 \\
\hline
\end{tabular}

\section{Sexual and reproductive health}

\section{Menstrual hygiene}

RKSK's menstrual hygiene scheme aims to promote use of sanitary napkins. About 1 in 3 girls in ages 10-14 were not aware of menstruation, with a slightly higher lack of awareness amongst rural girls. Amongst menstruating girls, less than 1 in 2 rural girls used either napkins alone or a combination with cloth, with considerably higher use of sanitary napkins in urban areas (Figure 1). Few girls received sanitary napkins from their schools or FLWs (4-13\% of unmarried and married older girls). Affordability was the leading reason reported for non-use of sanitary napkins, followed by concerns related to access, shyness and lack of awareness.
Figure 1: Use of sanitary napkins amongst adolescent girls in rural and urban areas

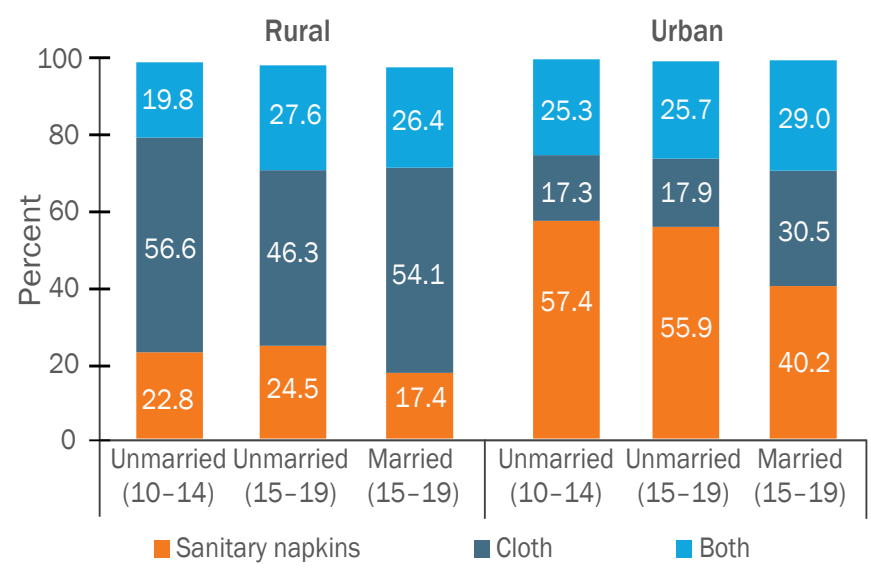

Genital infections and menstrual problems

Amongst older adolescents, 17-26 percent reported experiencing symptoms of genital infections (such as genital ulcers, itching, swelling, abnormal discharge) in the previous three months. About 2 in 3 boys, 1 in 3 married girls, and 1 in 5 unmarried girls with symptoms sought treatment (Figure 2). Boys sought treatment primarily from private sector providers and medical shops, while the majority of girls utilised private sector providers. Other sources of treatment were home remedies and unqualified practitioners, along with government providers (utilised by 10-18 percent of adolescents). Menstrual problems affected 10 percent of unmarried and married girls-of which 27 and 42 percent, respectively, reported seeking treatment, mostly in the private sector.

Figure 2: Prevalence of self-reported symptoms of genital infection and treatment-seeking, 15-19 years

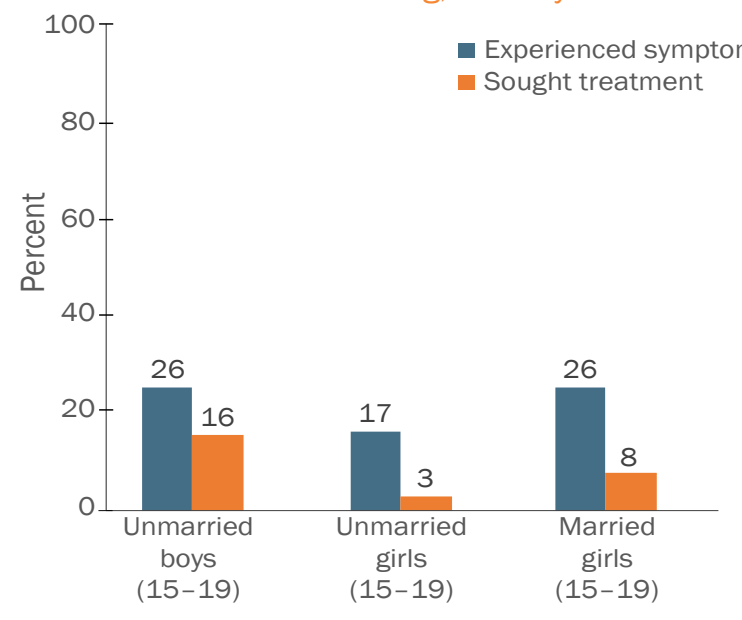

Sexuality and sexual health

Fourteen percent of boys and six percent of both unmarried and married girls reported having had premarital sex. Among older adolescents, a little over a quarter of unmarried girls and boys, and 1 in 2 married girls, knew that a woman can get pregnant at first sex. About 1 in 8 older boys and 3-4 percent of older girls demonstrated comprehensive knowledge of HIV/AIDS. 


\section{Contraception}

Correct, specific knowledge of condoms was reported by about 3 in 5 older adolescent boys and 2 in 5 married girls-and only 1 in 7 unmarried girls in ages 15-19. Correct knowledge of oral contraceptives and emergency contraception was considerably lower across all groups (Figure 3 ).

Figure 3: Correct, specific knowledge of contraception, 15-19 years

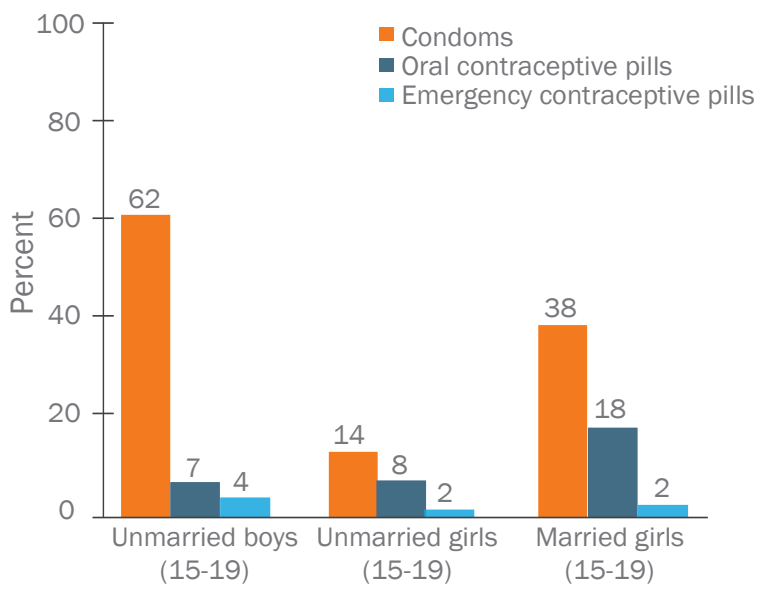

About 3 in 5 married girls reported wanting to space or limit childbearing. Eight percent of married girls who had begun cohabiting reported using contraception to delay the first birth, and seven percent reported currently using contraception (mostly condoms).

Figure 4: Contraceptive use and unmet need amongst married girls, 15-19 years

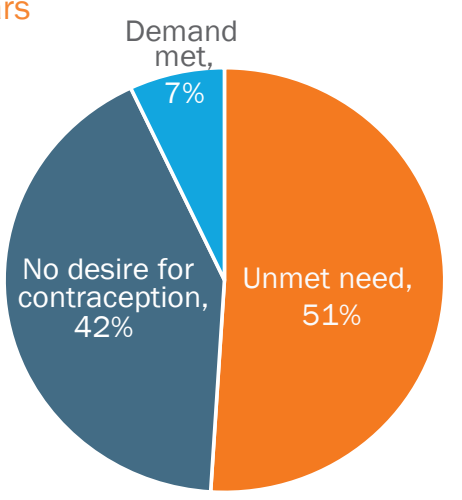

The remainder either had unmet needs (51\%) or did not desire to delay pregnancy at present (Figure 4). About one-half of all married girls reported they would feel shy approaching either a healthcare provider or medical shop for contraceptives.

\section{Maternal health}

About 3 in 10 married girls were aware that a pregnant woman should have at least four antenatal checkups. Fifity-one percent of cohabiting, married girls had begun childbearing. Most girls had not received the full continuum of maternal and child health services (Figure 5).

Figure 5: The continuum of maternal and child health care: (first birth)
98\% received at least
$79 \%$ delivered
$39 \%$ received one antenatal checkup in an institution any postnatal care
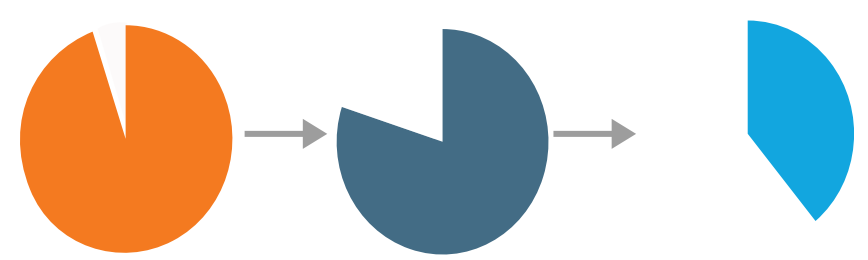

\section{Gender-based violence}

One-half of married girls cohabiting with their partners reported ever experiencing either emotional, physical or sexual violence within their marriage (Figure 6).

Figure 6: Violence ever experienced in marriage by married girls, $15-19$ years

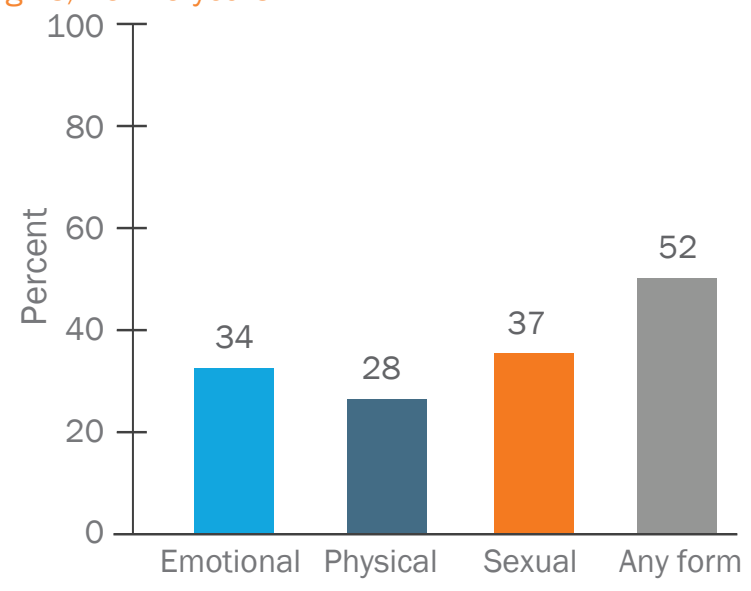

Forty-one percent of girls reported experiencing either physical or sexual violence within marriage in the last year. A considerable proportion of both boys and girls adhered to attitudes that normalise violence-in marriage, amongst peers, and in the community (Table 2). Same-sex physical fights appeared to be common amongst boys and younger girls.

Table 2: Involvement in and attitudes towards physical violence

\begin{tabular}{|lcccc|}
\hline & $\begin{array}{c}\text { Boys } \\
(10-14)\end{array}$ & $\begin{array}{c}\text { Unmarried boys } \\
(15-19)\end{array}$ & $\begin{array}{c}\text { Girls } \\
(10-14)\end{array}$ & $\begin{array}{c}\text { Unmarried girls } \\
(15-19)\end{array}$ \\
$\begin{array}{l}\text { Justified wife-beating if wife does not listen to } \\
\text { or obey husband }\end{array}$ & - & 22.9 & -19.7 \\
$\begin{array}{l}\text { Involved in physical fights with individuals of } \\
\text { the same sex }\end{array}$ & 46.4 & 24.8 & 29.5 & 16.9 \\
\hline $\begin{array}{l}\text { Believe it is acceptable to beat up someone } \\
\text { who insults a female family member }\end{array}$ & 48.4 & 47.5 & 35.2 & 34.0 \\
\hline
\end{tabular}


New burdens: prevalence and risk factors related to non-communicable diseases

UDAYA's estimates of mental health issues, injuries and substance use confirm the need for adolescentspecific strategies. Overall, older adolescent girls reported the highest prevalence of symptoms of depression (Figure 7). Amongst married girls, seven percent reported symptoms of moderate to severe depression in the previous two weeks, and seven percent also reported suicidal ideation.

Figure 7: Reported prevalence of symptoms of depression

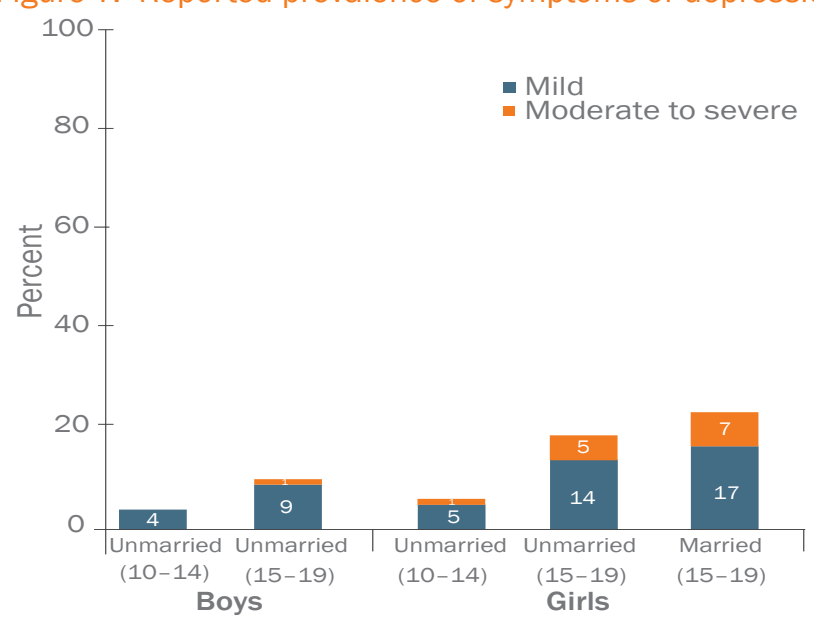

Injuries in the previous three months-highest among boys-were caused mostly by fights, falls or animal bites, with 9-11 percent of younger and older boys reporting injuries from road accidents. About 1 in 8 older boys reported using tobacco at least once per week, suggesting early exposure to risk factors for cardiovascular and lung disease. Reported alcohol use was minimal.

UDAYA also estimated physical inactivity, a leading risk factor for NCDs. Both younger and older boys, as well as younger girls, reported high levels of regular engagement in sports and gamescompared to one-half of unmarried older girls and 1 in 6 married girls.

\section{Wide opportunities exist for service outreach and tracking}

UDAYA indicated that most adolescents had heard of anganwadi workers (AWWs) and Accredited Social Health Activists (ASHAs)-suggesting that FLWs are well-placed to reach adolescents with information and services. However, just 40 percent of married girls reported interactions with FLWs, primarily for information related to reproductive health. Among students currently enrolled in school, between 15-32 percent reported receiving information from the School Health Programme or similar initiatives. About 1 in 5 unmarried girls and 1 in 10 married girls had been exposed to family life education. Virtually no respondents had utilised AFHCs in the previous year.
Figure 8: Services received by adolescents

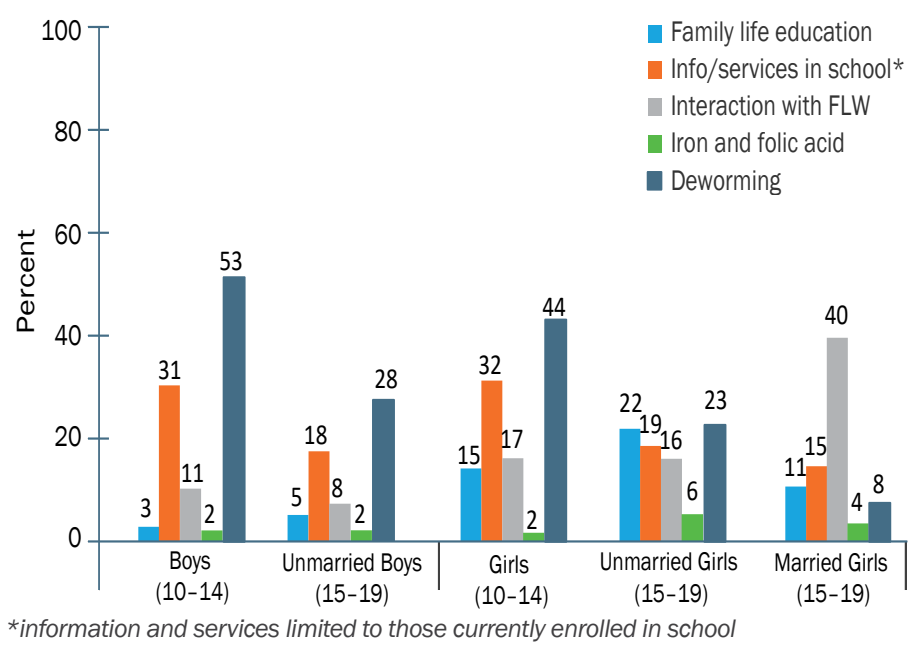

\section{Policy and programme insights}

With both national guidelines and increasing political priority, RKSK is positioned to address the specific needs of adolescents. Many aspects require coordination between a range of existing service providers at the community level, and integration with ongoing initiatives such as Kishori Balika Yojana.

In Bihar, implementation of RKSK's key servicesAFHCs, peer education, menstrual hygiene and iron folic acid supplementation-has focussed on 10 high priority districts, with roll-out of some components across the state. UDAYA was conducted in the initial stages of the programme; as data indicate, implementation and outreach thus far have been limited. While RKSK tracks monitoring data, analysis of indicator-based, disaggregated information will be required to assess both outreach and quality of specific services.

Qualitative interviews with policymakers and programme implementers indicated that human resource issues presented the primary challenge to effective roll-out of RKSK. Capacity building has been conducted at the state and district level amongst health care providers. However, delays in selection of peer educators, and attrition amongst those selected, have resulted in limited outreach at the community level.

Appointment of counsellors at AFHCs had been delayed as well. Multiple responsibilities for ANMs have limited the priority/efforts that they can offer adolescent-related programmes, such as increasing utilisation of, or serving as counselors for, AFHCs. Delays in procurement have also limited effective service delivery of commodities such as sanitary napkins and iron folic acid. Extra support within the deworming programme facilitated greater outreach, as confirmed by UDAYA's findings. 


\section{Recommendations}

\section{- Priority areas}

\section{Anaemia and healthy dietary practices}

Anaemia was widespread, particularly amongst girls. Given low reach of supplementation, improved distribution of iron and folic acid must be a priority, along with implementation research to inform a potential re-framing of the scheme. Understandable, context- specific information on nutrition and dietary practices should be a priority within health education programmes.

\section{Improve SRH knowledge and behaviour}

Gaps in knowledge about safe sex practices and contraception must be addressed urgently. Expansion of the Adolescent Education Programme and strengthening of age-appropriate family life or comprehensive sexuality education for all adolescents, is required. Evidence from NGOled programmes that combine sexuality and life skills education have shown promise in raising awareness of sexual and reproductive matters and helping to adopt protective behaviours. ${ }^{1,2}$ ASHAs must also improve provision of contraception to married girls to address the high unmet need documented in this group.

\section{Violence prevention and interventions}

The prevalence of intimate partner violence calls for strategies both to prevent violence and provide support services. Pilot interventions in India, such as Do Kadam Barabari ki Ore programme in Bihar, that hold promise are: gender transformative life skills education, sports coaching to change attitudes towards violence, and training FLWs to identify and provide services for women at risk of violence. ${ }^{3,4,5}$

\section{Mental health}

The prevalence of depression indicates the need for scalable strategies, especially for married girls. Emerging evidence in India suggests that community-based mental health interventions such as life skills education, counselling, and employing lay persons to screen/identify at-risk persons may help address symptoms of mental disorders. $6,7,8,9$

\section{Strengthen information dissemination}

RKSK is investing in peer educators, FLWs, and community events to bring information to adolescents. Peer educators and FLWs must be equipped with adolescent-specific communication materials, and must be trained in how to break down barriers to reach adolescents effectively.
UDAYA found that over 90 percent of older adolescent boys and girls had access to a mobile phone, and approximately 1 in 2 adolescent boys and 28-44 percent girls reported regular exposure to television. Accordingly, while community-based efforts should continue to focus on the most vulnerable, media and technology may help to expand and reinforce messaging.

\section{Ensure strong monitoring, evaluation and implementation research}

\section{Outreach activities of frontline workers}

FLWs reached less than 1 in 5 unmarried girls and boys, and community-based services such as deworming and sanitary napkins had far from universal outreach. Feasibility and effectiveness of existing FLWs in reaching adolescents should be examined to identify delivery improvement strategies and barriers to outreach.

\section{Peer educators}

As RKSK envisions peer educators as information sources as well as referral links to AFHCs, it will be critical to monitor their role in practice and examine whether and how they can best be deployed to improve knowledge and use of health services. Tracking of the implementation and costs associated with ongoing recruitment, training and attrition as adolescent peers age out of their roles is recommended-along with evaluation of the effectiveness of the programme.

\section{Adolescent Friendly Health Clinics}

AFHCs were virtually unused by adolescents, and a small proportion of adolescents reported use of any government services for symptoms of genital infections. RKSK must evaluate the continued use of AFHCs and whether outreach efforts are effective in increasing utilisation. Additional strategies such as expanding the provider base in the public and private sector and generating demand through social marketing should also be explored and evaluated.

\section{Acknowledgements}

The author is grateful to Nicole Haberland and K.G. Santhya for insightful comments on earlier versions of this brief, to Madhuri Das for the landscaping exercise, and to the Bill \& Melinda Gates Foundation and the David \& Lucile Packard Foundation for financial support for UDAYA.

This brief is based on data collected by the UDAYA study, the report of which is available at www. projectudaya.in. ${ }^{10}$ 


\section{References}

1. Pandey, N., S. J. Jejeebhoy, R. Acharya et al. 2016. Effects of the PRACHAR Project's Reproductive Health Training Programme for Adolescents: Findings from a Longitudinal Study. New Delhi: Population Council.

2. Mehra, S., R.R. Singh, V. Nair, et al. 2016. Addressing adolescent girls' vulnerability to HIV/AIDS: Lessons from the Meri Life Meri Choice project. New Delhi: Population Council.

3. Jejeebhoy, S.J., R. Acharya, N. Pandey et al. 2017a. The Effect of a Gender Transformative Life Skills Education and Sports-Coaching Programme on the Attitudes and Practices of Adolescent Boys and Young Men in Bihar. New Delhi: Population Council.

4. Jejeebhoy, S. J., K. G. Santhya, S. Singh et al. 2017b. Feasibility of Screening and Referring Women Experiencing Marital Violence by Engaging Frontline Workers: Evidence from Rural Bihar. New Delhi: Population Council.

5. Das, A, E. Mogford, S. Singh et al. 2012. "Reviewing responsibilities and renewing relationships: an intervention with men on violence against women in India" Culture, Health and Sexuality 14(6): 559-675.

6. Srikala, B and Kishore Kumar K. V. 2010. "Empowering adolescents with life skills education in schools - School mental health program: Does it work?," Indian Journal of Psychiatry 52(4): 344-49.

7. Balaji, M., T. Andrews, G. Andrew, et al. 2011. "The acceptability, feasibility, and effectiveness of a population based intervention to promote youth health: An exploratory study in Goa, India," Journal of Adolescent Health 48(5): 453-60.

8. Rajaraman, D., S. Travasso, A. Chatterjee, et al. 2012. Acceptability, feasibility and impact of a lay health counsellor delivered health promoting schools programme in India: a case study evaluation," BMC Health Services Research 12:127.

9. Patel, V., H. A. Weiss, N. Chowdhary et al. 2010. "Effectiveness of an intervention led by lay health counsellors for depressive and anxiety disorders in primary care in Goa, India (MANAS): a cluster randomised controlled trial." The Lancet 376(9758): 2086-95.

10. Santhya, K.G., R. Acharya, N. Pandey, et al. 2017. Understanding lives of adolescents and young adults (UDAYA) in Bihar. New Delhi: Population Council.

Study supported by

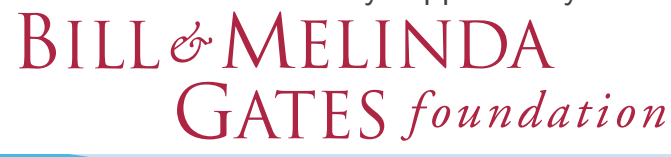

The Population Council confronts critical health and development issues-from stopping the spread of HIV to improving reproductive health and ensuring that young people lead full and productive lives. Through biomedical, social science, and public health research in 50 countries, we work with our partners to deliver solutions that lead to more effective policies,programs, and technologies that improve lives around the world. Established in 1952 and headquartered in New York, the Council is a nongovernmental, nonprofit organization governed by an international board of trustees.

\section{Suggested Citation}

Desai, S. 2017. Adolescent health: Priorities and opportunities for Rashtriya Kishor Swasthya Karyakram (RKSK). Policy Brief. New Delhi: Population Council. 